D.O.I.: $10.3895 / \mathrm{S} 1808-04482007000100012$

\title{
TIPOLOGIAS DE AGLOMERAÇÕES PRODUTIVAS DE EMPRESAS: UM ESTUDO DE CASO
}

\section{TIPOLOGIES OF PRODUCTIVE AGGLOMERATIONS: A CASE STUDY}

\author{
Regina Negri Pagani ${ }^{1}$; Luis Mauricio de Resende ${ }^{2}$ \\ ${ }^{1}$ Universidade Tecnológica Federal do Paraná- UTFPR - Ponta Grossa - Brasil \\ jrpagani@uol.com.br \\ ${ }^{2}$ Universidade Tecnológica Federal do Paraná - UTFPR - Ponta Grossa - Brasil \\ lmresende@utfpr.edu.br
}

\begin{abstract}
Resumo
Esse estudo objetivou caracterizar a aglomeração produtiva do setor de Móveis de Metal $e$ Sistemas de Armazenagem e Logística de Ponta Grossa, PR, segundo as tipologias apresentadas na literatura. Foi realizada uma pesquisa exploratória por acessibilidade, com abordagem quantitativa e procedimentos qualitativos complementares. Os dados foram coletados através de questionário e entrevistas com os sócios elou proprietários das empresas do setor. A análise dos dados aponta que o setor se trata de aglomeração produtiva de empresas em estágio embrionário de interação.
\end{abstract}

Palavras-chave: Aglomerações Produtivas de Empresas, Móveis de Metal, Sistemas de Armazenagem e Logística.

\section{Introdução}

Marshall foi o pioneiro a discutir o desenvolvimento industrial a partir das aglomerações de empresas no final do século XIX. Na época, porém, o conceito dominante era o das grandes economias de escala, protagonizadas pelas grandes corporações. Foi somente por volta de 1980 que observadores perceberam um setor de pequenas e médias empresas que surgiam, sem nenhum apoio público, à sombra dos grandes distritos industriais italianos: a terceira Itália, composta por pequenas e médias empresas dinâmicas, com especialização flexível e intensa interação entre elas, apresentando índices surpreendentes de crescimento econômico na região (MEYER-STAMMER \& HARMES-LIEDTKE, 2005).

Em 1990, Porter publica “A vantagem competitiva das nações” que enfatizava a importância dos clusters para a competitividade industrial, tornando-se o marco de intensos trabalhos com aglomerações produtivas. 
As aglomerações de empresas têm sido objeto de estudo em outros paises e no Brasil. $\mathrm{O}$ Governo do Estado do Paraná iniciou em 2005 um trabalho de pesquisa para mapear e identificar estatisticamente as aglomerações de empresas existentes no Estado. A pesquisa previa, realizada pela SEPL e IPARDES, detectou no município de Ponta Grossa a existência de uma aglomeração produtiva de empresas no setor de Móveis de Metal e Sistemas de Armazenagem e Logística. Esta aglomeração, segundo a metodologia da SEPL e IPARDES, configura-se como uma aglomeração que se destaca duplamente: quer pela sua importância para uma região, quer pela sua importância para o setor de atividade econômica no Estado (SEPL e IPARDES, 2006).

O bjetivo deste trabalho, que é parte de uma dissertação de mestrado, é caracterizar o referido setor, visando nortear ações de iniciativa pública ou privada que busquem organizar a aglomeração e fomentar sua competitividade econômica.

\section{Aglomerações produtivas de empresas: principais abordagens}

A teratura aponta várias abordagens sobre aglomerações produtivas de empresas (MARSHAL, 1920; KRUGMAN, 1991, 1998a, 1998b; CASAROTTO e PIRES, 2001; CASSIOLATO e LASTRES, 2003; SUZIGAN, 2003, 2005; PORTER, 1990, 1998).

A teoria Marshalliana é o ponto de partida para todos os estudos relacionados a aglomerações de empresas. Marshall (1920) observou os distritos industriais na Grã-Bretanha, no final do século XIX, e verificou que a presença concentrada de firmas em uma mesma região pode prover ao conjunto dos produtores vantagens competitivas que não seriam verificadas se eles estivessem trabalhando de forma isolada. Os principais fatores que justificam a importância da localização geográfica são as condições físicas e climáticas e o surgimento de um mercado de trabalho robusto e constante de trabalhadores especializados. Marshall denominou esses fatores de “economias externas” (MARSHALL, 1920; MEYER-STAMER e HARMES-LIEDTKE, 2005).

A abordagem da Nova Geografia Econômica (NGE), originada da teoria clássica que busca explicar a natureza da aglomeração, destaca a importância das externalidades Marshallianas, tais como mercados de trabalho especializados, fatores históricos e geográficos e a localização de indústrias de serviço. Para Krugman (1991, 1998a, 1998b), as economias de escala impulsionam a concentração geográfica de algumas atividades, e as economias externas locais têm caráter incidental e operam forças de atração (forças centrípetas) e repulsão (forças centrífugas) de empreendimentos para determinada aglomeração de empresas. Assim, a dinâmica do processo de aglomeração dependerá do embate dessas forças centrípetas e centrífugas presentes no local.

A abordagem da economia das empresas busca explicar as fontes de prosperidade das nações modernas na economia global. Estas fontes estão estribadas na economia das empresas, e o 
mapa econômico mundial é dominado por clusters: massas críticas de aglomerações produtivas de empresas localizadas em uma região com um sucesso competitivo em áreas específicas. A competição entre as empresas, e a cooperação vertical, são as principais formas de aumentar a competitividade de uma nação ou cluster (PORTER, 1990, 1998, 1999, 2001).

A abordagem da economia da inovação (CASSIOLATO e LASTRES, 2003; SANTOS, 2005; BRESCHI e MALERBA apud GARCIA, 2001) tem como foco o desenvolvimento tecnológico e a formação de sistemas de inovação decorrentes da interação das empresas e outras organizações. Para Cassiolato e Lastres (2003), inovação e conhecimento configuram-se cada vez mais como elementos centrais da dinâmica e do crescimento de organizações, de regiões e nações. A inovação e o aprendizado são fortemente influenciados por contextos econômicos, sociais e políticos específicos, e são vistos por estes autores como processos dependentes de interações. Estas interações ocorrem principalmente por meio do estabelecimento de códigos comuns de comunicação e coordenação.

A abordagem da eficiência coletiva tem Schmitz (1997, 1998) como principal autor. Segundo ele, é a combinação de dois fatores, o das economias externas locais espontâneas e das ações conjuntas deliberadas das empresas do setor, que produz a vantagem competitiva denominada por ele de eficiência coletiva. Essas ações conjuntas podem ocorrer de duas formas, dimensionadas na Figura 1.

Figura 1 - Cooperação em uma aglomeração produtiva

\begin{tabular}{|l|l|l|}
\hline & Bilateral & Multilateral \\
\hline Horizontal & $\begin{array}{l}\text { e.g. Compartilhamento de equipamentos e troca } \\
\text { de informações }\end{array}$ & e.g. Associações de produtores \\
\hline Vertical & $\begin{array}{l}\text { e.g. Associação de fornecedores e usuários para } \\
\text { melhoria de componentes usuários }\end{array}$ & e.g. Alianças na cadeia de valores \\
\hline
\end{tabular}

Fonte: Adaptado de Schmitz, 1997; Meyer-Stamer e Harmes-Liedtke (2005).

A abordagem sistêmica, proposta por Ludwig von Bertalanfy CHIAVENATO, 2004) retrata a natureza sistêmica das aglomerações produtivas de empresas. A essência do pensamento sistêmico é a idéia de um conjunto de elementos interdependentes e interagentes; um grupo de unidades combinadas que formam um todo organizado para realizar objetivos comuns, cujo resultado final é obtido de forma sinérgica. O modelo sociotécnico de Tavistock, expresso na Figura 2, resume os dois aspectos mais importantes de uma aglomeração produtiva: o técnico e o social. 
Figura 2 - O aglomerado de empresas sob o enfoque sistêmico-sociotécnico

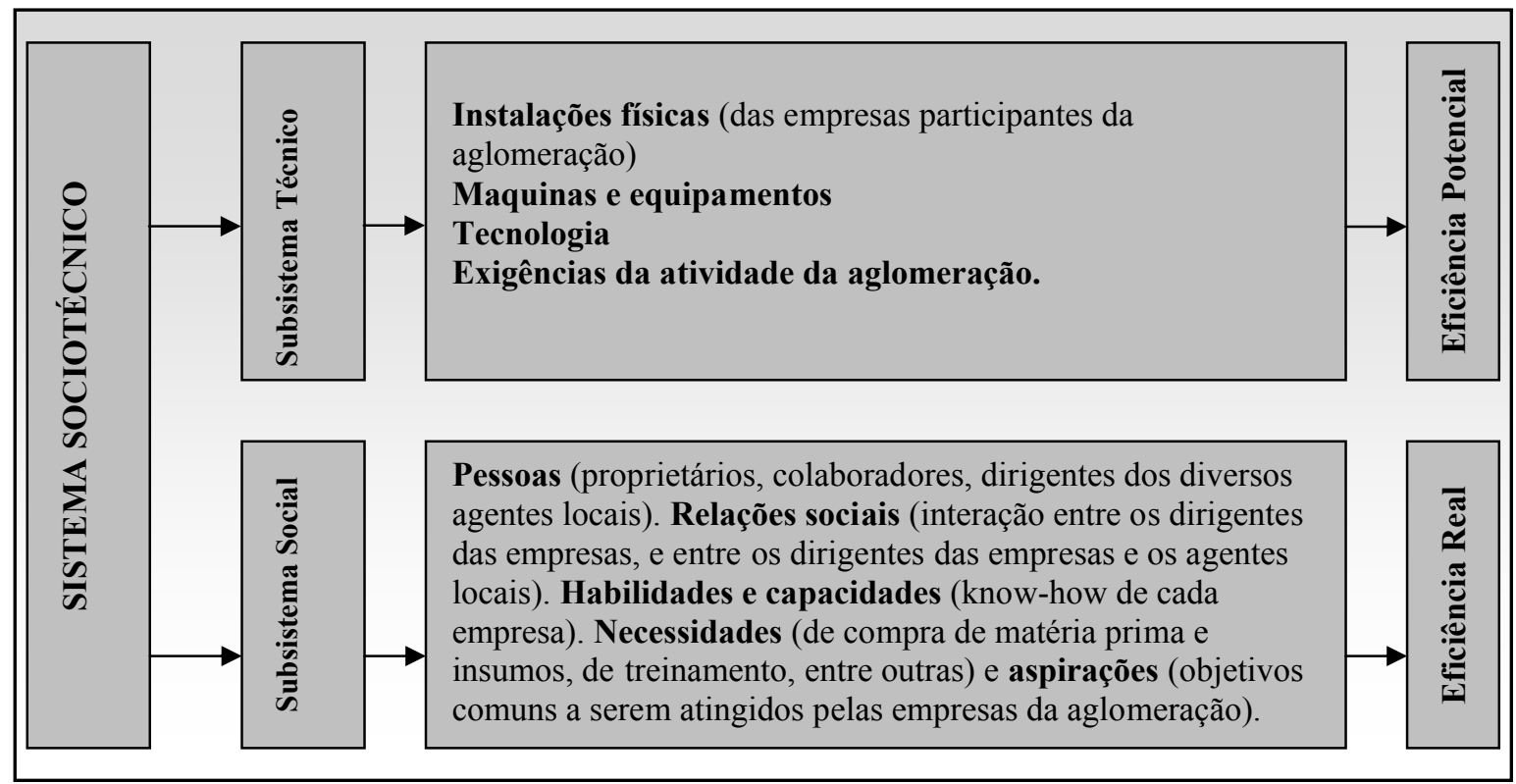

Fonte: Adaptado de Chiavenato, 2004.

As abordagens sobre aglomerações de empresas e características enfáticas estão sintetizadas na Figura 3.

Figura 3 - Características enfáticas das abordagens de aglomerações territoriais

\begin{tabular}{|c|c|}
\hline ABORDAGENS & ÊNFASE \\
\hline 1. Economias Externas Marshallianas (Marshall) & $\begin{array}{l}\text { Enfatiza a importância da localização geográfica; } \\
\text { interação entre as pequenas empresas propicia que } \\
\text { estas se apropriem de economias de escala; } \\
\text { pequenas empresas são mais ágeis e eficientes do } \\
\text { que grandes corporações. }\end{array}$ \\
\hline 2. Nova Geografia Econômica (Krugman) & $\begin{array}{l}\text { Externalidades, forças centrípetas e centrífugas. } \\
\text { Aglomerações são produtos de "acidentes" } \\
\text { históricos. }\end{array}$ \\
\hline 3. Abordagem da economia das empresas (Porter) & $\begin{array}{l}\text { Ênfase na rivalidade como fator de } \\
\text { competitividade, cooperação verticalizadas. }\end{array}$ \\
\hline 4. Economia da Inovação (Lastres e Cassiolato) & Ênfase no aprendizado interativo e na inovação. \\
\hline 5. Ações conjuntas e eficiência coletiva (Schmitz) & $\begin{array}{l}\text { Enfatiza a eficiência coletiva, que é o produto das } \\
\text { economias externas incidentais e ação conjunta } \\
\text { deliberada entre os vários atores da aglomeração } \\
\text { (cooperação horizontal e vertical). }\end{array}$ \\
\hline 6. Abordagem sistêmica (Ludwig von Bertalanfy) & $\begin{array}{l}\text { Enfatiza a idéia de um conjunto de elementos } \\
\text { interagentes, buscando através da sinergia a } \\
\text { negentropia no macro-ambiente. }\end{array}$ \\
\hline
\end{tabular}

Fonte: Elaborado pelo autor. 


\subsection{Tipologias de aglomerações, características essenciais e classificações}

A literatura apresenta uma variada tipologia de aglomerações produtivas de empresas, uma vez que estas são inerentemente idiossincráticas em natureza, com diferentes aplicações de conceito de acordo com os vários contextos (ENRICO e GRANDI, 2005). A Figura 4 apresenta os elementos podem ser adotados como chave para as noções gerais de aglomerações produtivas.

Figura 4 - As sete características essenciais das aglomerações produtivas

\begin{tabular}{|ll|l|}
\hline \multicolumn{2}{|c|}{ Características } & \multicolumn{1}{c|}{ Descrição } \\
\hline 1. Concentrações geográficas & $\begin{array}{l}\text { Empresas se localizam em proximidade geográfica devido a fatores } \\
\text { importantes, tais como economias externas de escala, bem como fatores } \\
\text { mais amenos tais como capital social e processos de atividades. }\end{array}$ \\
\hline 2. Especialização & $\begin{array}{l}\text { As aglomerações estão no centro de atividades principais as quais todos } \\
\text { os agentes estão ligados }\end{array}$ \\
\hline 3. Agentes Múltiplos & $\begin{array}{l}\text { As aglomerações e as suas iniciativas não consistem apenas em } \\
\text { empresas, mas também envolvem autoridades públicas, instituições de } \\
\text { ensino e de colaboração, e instituições do setor financeiro. }\end{array}$ \\
\hline 4. Competição e cooperação & Esta combinação caracteriza as relações entre os agentes interligados. \\
\hline 5. Massas críticas & \begin{tabular}{l} 
É requerida para alcançar dinamismo interno. \\
\hline 6. $\quad$ ciclo de vida de uma \\
aglomeração
\end{tabular} & $\begin{array}{l}\text { As aglomerações e suas iniciativas não são fenômenos temporários de } \\
\text { curta duração, mas são progressivos com perspectivas de longa duração. }\end{array}$ \\
\hline 7. Inovação & $\begin{array}{l}\text { Empresas aglomeradas são envolvidas em processo de mudanças } \\
\text { tecnológicas, comerciais e/ou organizacionais. }\end{array}$ \\
\hline 8. Cultura & $\begin{array}{l}\text { Elemento chave, um bem de grande valor para o desenvolvimento das } \\
\text { dinâmicas de uma aglomeração. Fator amplamente reconhecido na } \\
\text { literatura, porém raramente considerado ao serem elaboradas políticas } \\
\text { publicas de apoio às aglomerações. }\end{array}$ \\
\hline
\end{tabular}

Fonte: Elaborado a partir de Enrico e Grandi (2005).

As aglomerações são geralmente definidas e conceituadas de acordo com o seu nível de desenvolvimento. Suzigan (2003) observa o grau de importância econômica para o setor e para a região. Frigero (2006), leva em conta o grau de desenvolvimento econômico, técnico e cultural. Lastres e Cassiolato (2003) focam o grau de organização e conhecimento da aglomeração.

A Figura 5 apresenta as classificações segundo os autores acima mencionados.

Figura 5. Tipologia das aglomerações produtivas segundo o nível de desenvolvimento

\begin{tabular}{|c|c|c|c|c|}
\hline 딕 & 5 & Meta Distritos & & \\
\hline \multirow{5}{*}{ 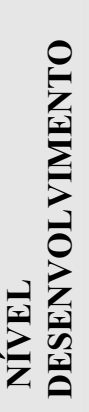 } & 4 & Cadeia "Filiera" & $\begin{array}{l}\text { Núcleo de Desenvolvimento } \\
\text { Setorial-Regional }\end{array}$ & \\
\hline & 3 & Distritos Industriais & Vetores Avançados & $\begin{array}{l}\text { Sistemas Produtivos e } \\
\text { Inovativos Locais }\end{array}$ \\
\hline & 2 & Sistemas Produtivos Locais & Vetor Desenvolvimento Local & Sistemas Produtivos Locais \\
\hline & 1 & $\begin{array}{l}\text { Agregações } \quad \text { Produtivas } \\
\text { Menores }\end{array}$ & Embrião & Arranjo Produtivo Local \\
\hline & & Frigero (2006) & Suzigan (2003) & Lastres e Cassiolato (2003) \\
\hline
\end{tabular}

Fonte: Elaborado pelo autor. 


\section{Procedimentos metodológicos}

Do ponto de vista da sua natureza, trata-se de pesquisa aplicada (SILVA e MENEZES, 2001). Do ponto de vista da forma de abordagem a pesquisa é basicamente quantitativa com procedimentos qualitativos complementares, visando atender a todos os objetivos da pesquisa (SILVA e MENEZES, 2001). Do ponto de vista de seus objetivos, a pesquisa é descritiva. O método do procedimento utilizado foi o estudo de caso (GIL, 1999; YIN, 2001). A população é composta por dezessete empresas, e a amostra configurou-se como não probabilística, por acessibilidade. A técnica utilizada para a coleta de dados nas empresas constituiu-se da aplicação de um questionário com questões fechadas e abertas (LAKATOS e MARCONI, 2001) e entrevista realizada junto ao sócio-proprietário.

\section{A aglomeração produtiva de móveis de metal e sistemas de armazenagem e logística de ponta grossa}

\subsection{Origem e caracterização das empresas}

A aglomeração é atualmente composto por 17 empresas, que são oriundas da primeira empresa constituída no setor em 1973, com a produção de móveis de metal, e mais tarde com a produção de sistemas de armazenagem e logística. A produção, tanto de móveis de metal como de sistemas de armazenagem e logística, utiliza processos e equipamentos e habilidades de mão-deobra similares. A principal matéria-prima utilizada - o aço - é a mesma para todas as empresas. A mudança está no formato em que este é fornecido: em forma de chapas, barras ou perfilados, dependendo do produto final. A diferença ocorre no detalhamento do processo de produção. Uma vez que os processos de produção, apesar de similares, possuem diferenças nos detalhes e resultam em produtos diferentes voltados a públicos consumidores distintos, neste aglomerado produtivo torna-se possível identificar dois segmentos distintos: um segmento voltado à produção de móveis de metal e cofres, e outro voltado à produção de sistemas de armazenagem.

Dentre as 15 empresas visitadas, dez são de pequeno porte (EPP), e cinco de médio porte (EMP). O número médio de funcionários nas empresas em 2006 é 34 entre as EPPs e de 245 entre as EMPs. As quinze empresas geram um total de 1.561 empregos formais diretos. $\mathrm{O}$ faturamento anual médio estimado em 2005 foi de $\mathrm{R} \$ 211.000 .000,00$ (duzentos e onze milhões de reais). Na Tabela 10 estão descritos a produção do setor em 2005 , assim como o nível de utilização da capacidade instalada. 
Tabela 1. Produção em 2005 e nível de utilização da capacidade

\begin{tabular}{llll}
\hline \multirow{2}{*}{ Empresas } & \multicolumn{2}{l}{ Produção em 2005 } & \begin{tabular}{l} 
Nível de utilização da \\
Capacidade instalada \\
\cline { 2 - 4 }
\end{tabular} \\
\cline { 2 - 4 } & Toneladas & \% no setor & $57,2 \%$ \\
\hline Pequeno porte & 12.096 & $19,76 \%$ & $80 \%$ \\
Médio porte & 49.092 & $80,24 \%$ & $68,6 \%$ \\
\hline Total / Média & 61.188 & $100 \%$ & \\
\hline
\end{tabular}

Quando da fundação das empresas, 60\% dos empresários fundadores das EPP possuíam ensino superior completo ou incompleto, e apenas $20 \%$ empresários fundadores das EMPs possuíam o ensino superior completo.

Quanto ao tipo de gestão, dentre as dez EPPs 60\% tem gestão do tipo familiar e 30\% gestão profissionalizada. A totalidade das EMPs têm gestão familiar. Não obstante, alguns dirigentes de EMPs estão sempre em busca de capacitação profissional, o que não ocorre com os dirigentes das EPPs.

\subsection{Qualificação da mão-de-obra}

As demandas de mão-de-obra para os níveis técnicos são supridas através da contração de estagiários que, se bem sucedidos nos estágios, tornam-se efetivos. Os engenheiros precisam ser contratados fora da região, tendo em vista não existir formação específica na cidade.

A maior criticidade está na contração de mão-de-obra empregada para as atividades de chão de fábrica, pois não existe na região grande oferta de mão-de-obra qualificada para as funções mais elementares comuns à todas as empresas do setor, como soldadores, pintores, entre outras.

A Figura 6 apresenta as formas de realização do treinamento e qualificação da mão-de-obra.

Figura 6 - Treinamento e/ou qualificação e capacitação da mão-de-obra

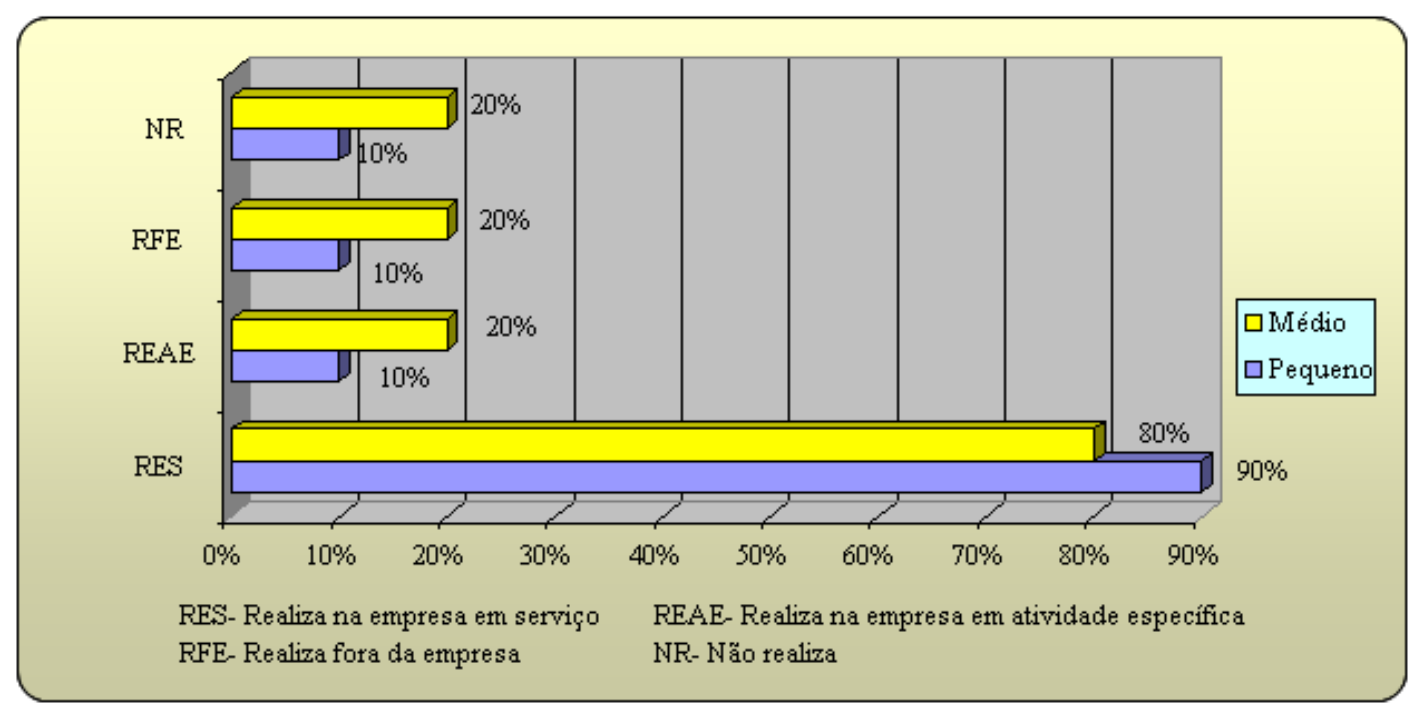


Como a maioria das empresas - 90\% das EPPs e 80\% das EMPs - utiliza a técnica de transferência interna de conhecimento "aprender-fazendo" (learning-by-doing), os colaboradores são contratados e imediatamente colocados em suas funções; quando nada sabem sobre sua função, estes trabalhadores nos primeiros dias observam os colegas e vão aos poucos sendo inseridos em suas atividades. Quando já possuem algum conhecimento prévio, são diretamente encaminhados para seus postos e, em caso de dúvida quanto à execução de suas tarefas, questionam direto ao supervisor ou chefe de produção. Apenas $15 \%$ das empresas do setor realizam o treinamento em atividades específicas destinadas para este fim; apenas 15\% das empresas realizam o treinamento fora da empresa, em cursos específicos; e 15\% não realizam nenhum tipo de treinamento.

\subsection{Relações interempresariais e cooperação multilateral}

As atividades atualmente desenvolvidas de forma cooperativa, bem como sua freqüência, estão ilustradas na Figura 7. Observa-se que $66 \%$ da forma de cooperação ocorre através de troca e/ou empréstimo de materiais, tais como chapas, componentes e tintas.

Figura 7 - Atividades atualmente desenvolvidas de forma cooperativa / compartilhada

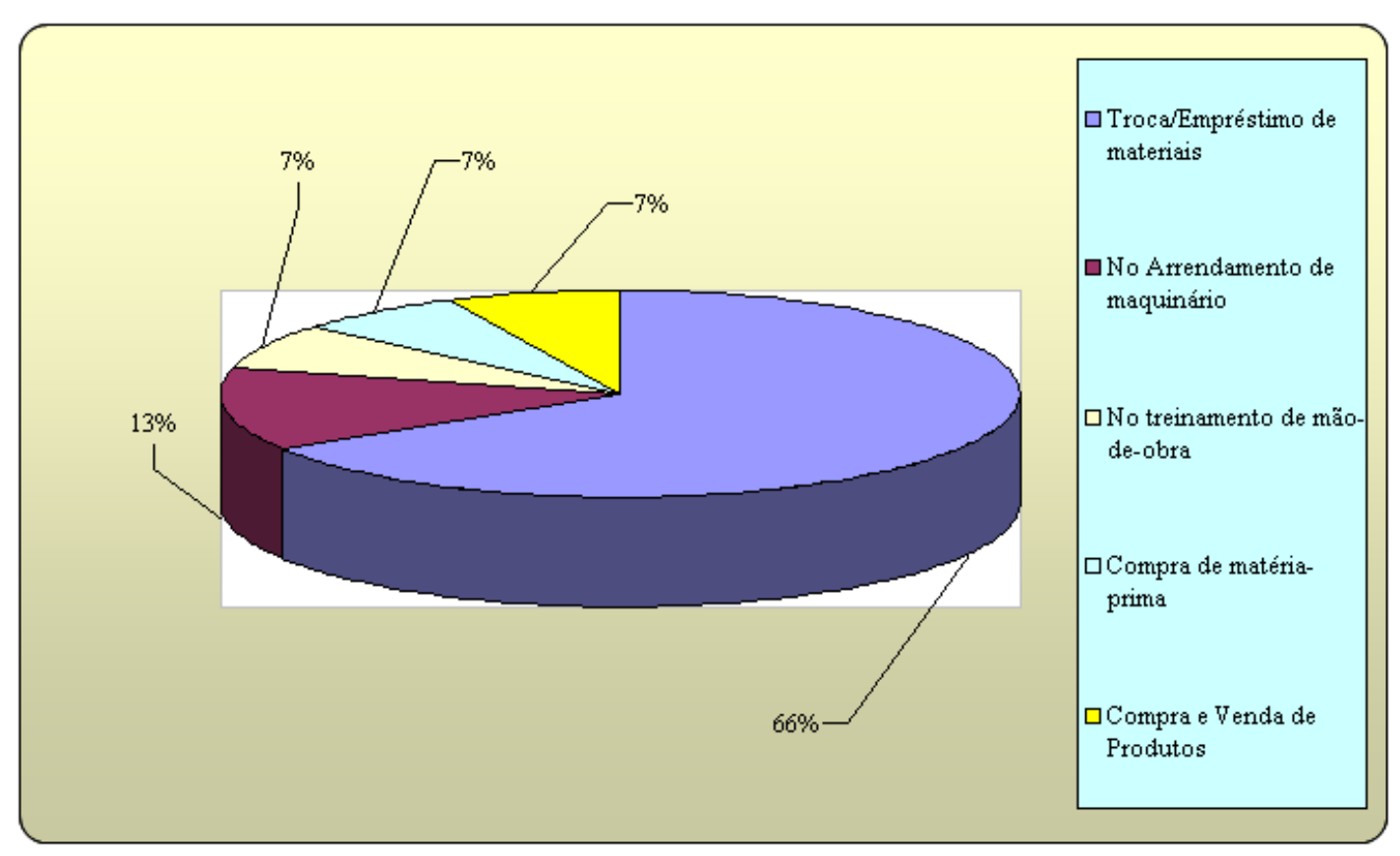

Foi também investigado qual a pretensão dos empresários de futuramente trabalharem de forma cooperativa, caso um APL venha a se estruturar no setor. As formas de compartilhamento gerais, apresentadas na Tabela 9, contemplam aspectos administrativos, comerciais e organizacionais. 
As atividades que despertam o maior interesse entre os empresários são: manutenção de um escritório para exportação; contratação e treinamento de pessoal; compra compartilhada de insumos e matéria-prima.

A manutenção de um escritório para exportação obteve a concordância total dos entrevistados. Isto se deve ao fato de que os custos com um despachante idôneo e eficaz têm um custo elevado para ser arcado por uma única empresa. O trabalho conjunto beneficiaria a todos e as empresas seriam capazes de manter um serviço de alta qualidade e com retornos garantidos, o que não é possível alcançar de forma isolada.

A contratação e treinamento de pessoal, e a compra compartilhada de insumos e matériaprima, ficaram em segundo lugar de interesse. Quanto ao treinamento e contratação, os favoráveis preferem que estas atividades ocorram de forma compartilhada apenas em níveis básicos onde as atividades ou funções são comuns a todas as empresas do setor. Para as funções estratégicas, eles acreditam que o treinamento deve ser realizado pela própria empresa, pois cada empresa possui sua especialidade que se constitui no seu diferencial de negócio, e isto eles não gostariam de partilhar.

Tabela 1 - Atividades de compartilhamento e cooperação pretendidas pelos empresários

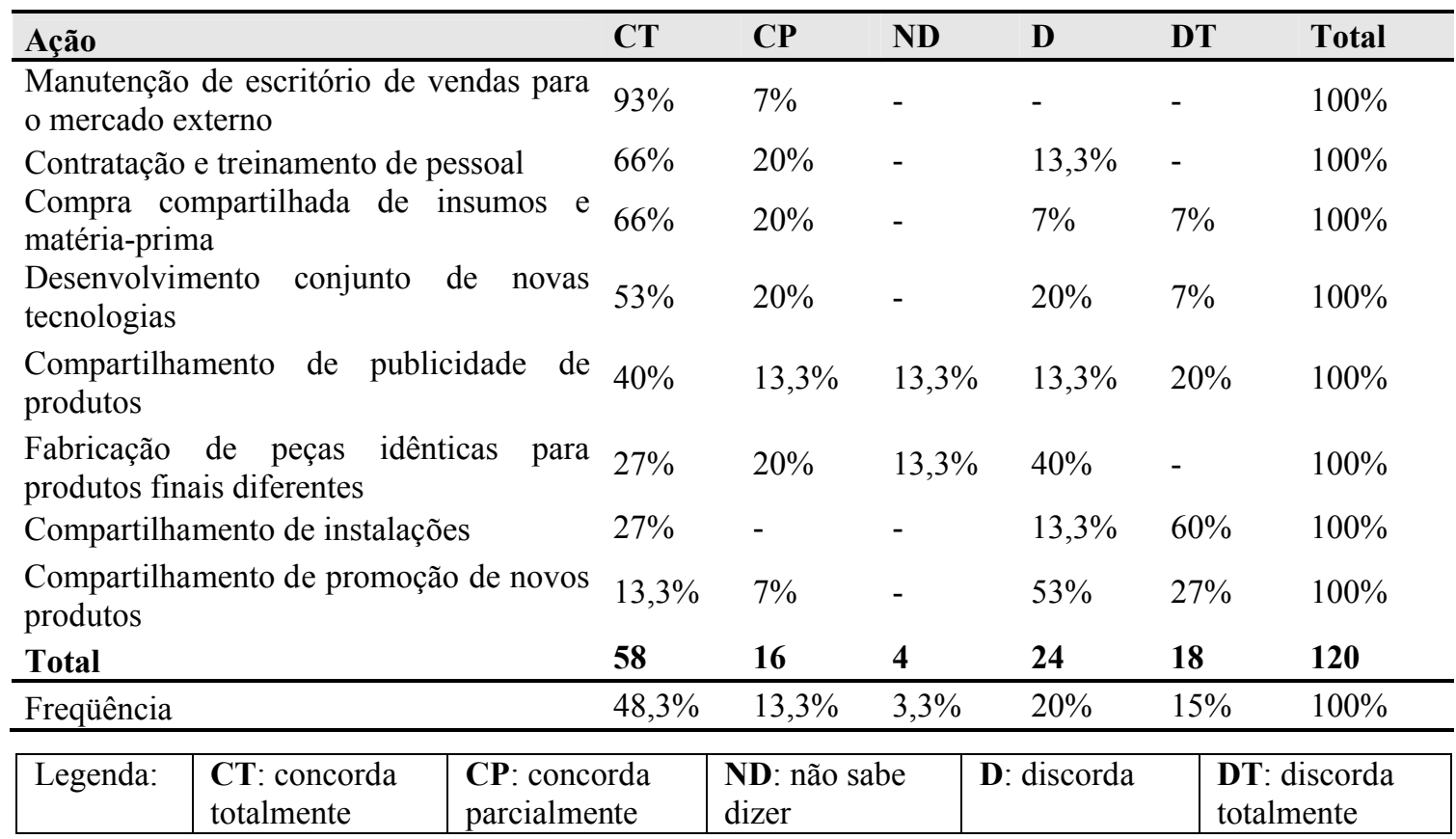

Fonte: Adaptado de Pagani et al., 2006a.

A compra compartilhada de insumos e matéria-prima pode facilitar as formas de pagamento e alcançar preços mais acessíveis. No entanto, para os empresários, esta forma de compartilhamento deve ser amadurecida e ocorrer através de contrato. Isto evita situações constrangedoras, como uma situação ocorrida no passado, quando um dos empresários realizou uma compra que deveria ser partilhada, em nome de um grupo, e acabou tendo que arcar sozinho com os pagamentos e com o uso da matéria-prima. 
O desenvolvimento de novas tecnologias apresenta uma situação semelhante à contração e treinamento de pessoal, pois algumas tecnologias não podem ser compartilhadas, principalmente àquelas que se referem a produtos finais, como no caso de sistemas de armazenagem.

O compartilhamento de publicidade de produtos desperta um índice médio de interesse entre os empresários. Porém, o Marketing é uma função complexa que normalmente não pode ser bem desempenhada por pequenas empresas atuando isoladamente. A realização conjunta desta atividade possibilita obter uma melhor imagem do produto, com melhor cobertura de mercado, bem como a abertura de novos canais, o que, conseqüentemente, leva a explorar novas oportunidades e novos mercados com investimentos consideravelmente mais baixos. Além disso, a existência de um aglomerado de empresas trabalhando na mesma atividade confere à localidade uma boa reputação relacionada àquela atividade, fazendo com que os compradores tenham mais confiança em adquirir produtos daquela região, sendo este um fator decisivo na hora da opção de compra. Para que isto ocorra, é necessário que haja ações deliberadas conjuntas entre as empresas, compartilhando a propaganda e o marketing, combinando recursos de vendas. As demais atividades obtiveram índices de médio e baixo interesse.

A interação social atualmente existente entre os empresários é de $45 \%$, e as atividades compartilhadas são atividades culturais, recreativas, esportivas e encontros informais. No entanto, $55 \%$ declararam não ter nenhum tipo de relacionamento social com outros empresários.

As relações de interação com os fornecedores e empresas correlatas estão apresentadas na Figura 8 .

Figura 8 - Interação com fornecedores

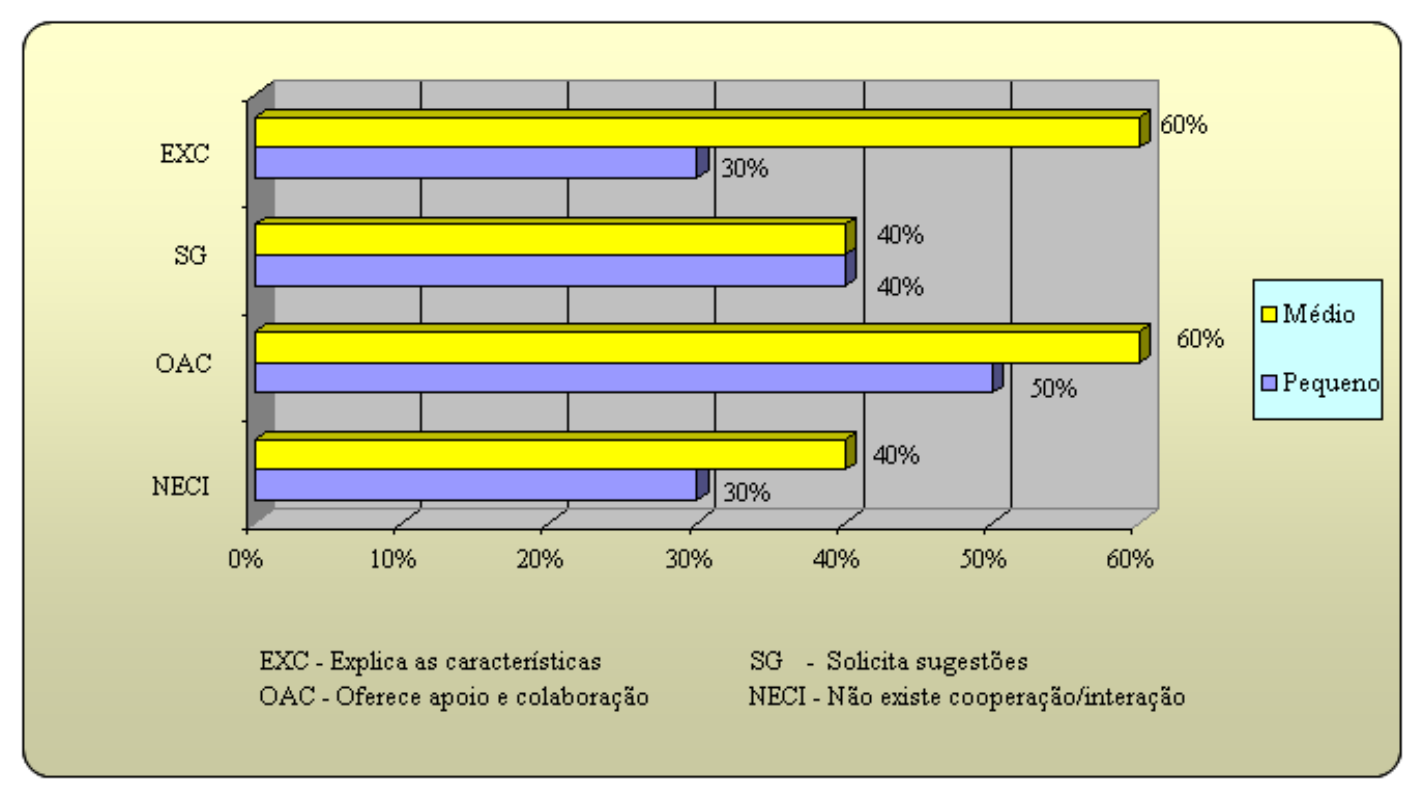


Segundo Porter (1990), estas relações configuram num importante fator para aumentar a competitividade das empresas locais. Conforme ilustrado na Figura 8, observa-se que 35\% das empresas do setor declararam não manter nenhum tipo de interação ou atividades de cooperação com os fornecedores, o que revela um relacionamento distanciado entre estas partes.

As demais empresas do setor disseram manter algum tipo de interação e cooperação. Esta interação e cooperação ocorrem das seguintes maneiras: o fornecedor apóia de alguma maneira o empresário na medida em que oferece informações e explicações sobre as peculiaridades do produto que esta comercializando, tais como maneira mais adequada de manuseá-lo ou processá-lo durante a industrialização dos produtos; solicita sugestões quanto às características do produto comercializado, se este apresenta alguma dificuldade de utilização, entre outros.

A pesquisa de campo revelou que este relacionamento é incipiente e distante, e que a interação existente não é ideal. As empresas mais favorecidas são as EMPs, que recebem mais orientações do que as EPPs, mas mesmo os empresários das EMPs não se mostraram tão entusiasmados ao relator o nível de relacionamento com os fornecedores.

\subsection{Principais destinos da produção}

Os clientes potenciais das empresas do setor se localizam em outros estados, $80 \%$, conforme ilustrado na Figura 9. No estado do Paraná as EPPs têm uma porcentagem maior de clientes, representando $21 \%$ de suas vendas. Para as EMPs a venda no estado representa apenas 8,8\% de suas vendas totais.

Figura 9 - Localização dos clientes potenciais / destino principal das vendas em 2005

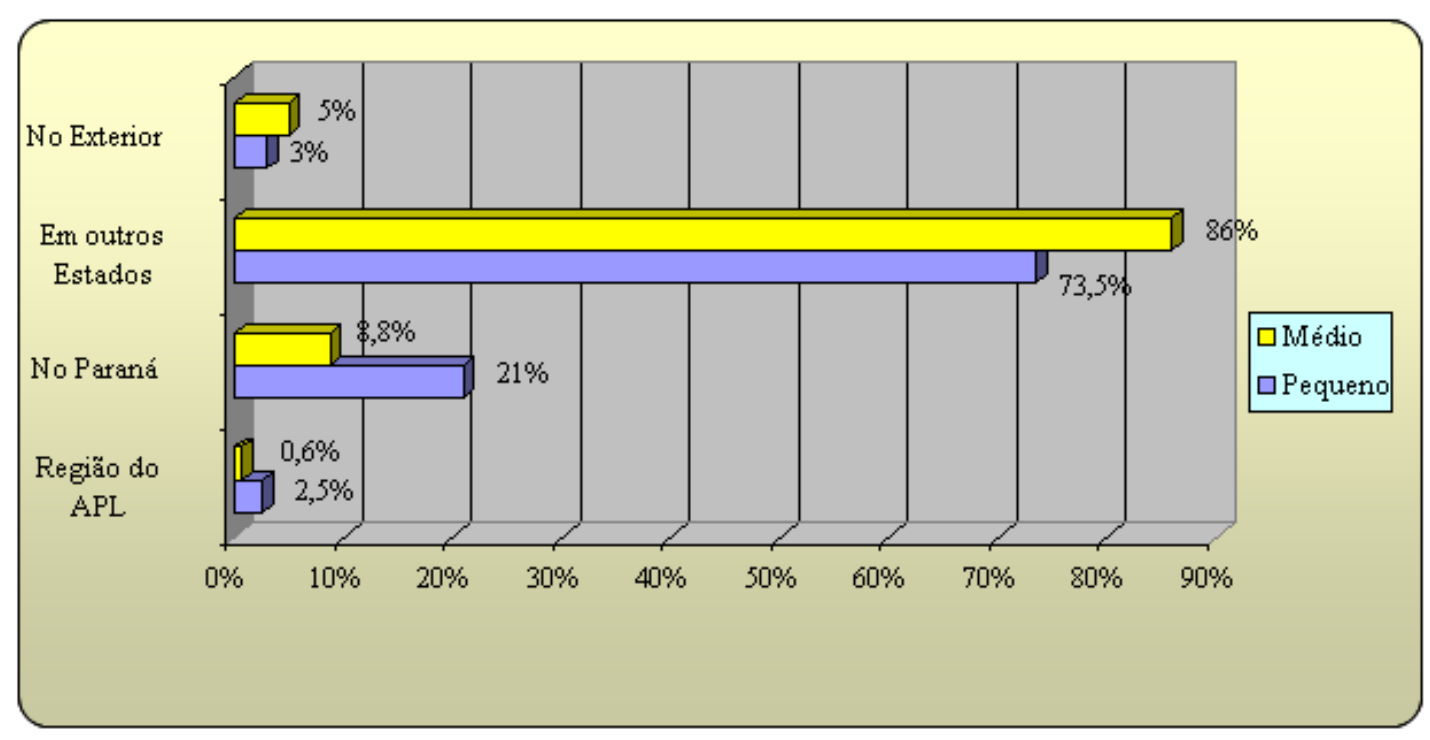


O índice de exportação é de 4\%. Algumas das causas mencionadas pelos empresários são: taxa de câmbio atual pouco atrativa; o custo que a manutenção de um despachante idôneo e eficaz significa para uma única empresa arcar sozinha; a dificuldade em atender a demanda em termos de quantidade; necessidade de adequação da produção às normas de qualidade exigidas para exportação, pois sem atender as normas de padronização internacional, o setor não tem acesso ao mercado internacional.

As empresas comercializam a produção através de diversos canais, apresentados na Tabela 3. Os mais utilizados são a representação comercial, com 36,7\%; venda direta ao cliente, com $22,3 \%$ e licitação, com 22\%. Algumas empresas chegam a utilizar $90 \%$ da licitação como canal de comercialização. A venda direta ao cliente ocorre em função dos clientes já terem conhecimento das empresas e acabam por procurá-la através de indicações de outros clientes. Não existe um acordo entre as empresas no que se refere às exposições em feiras, ou marketing conjunto.

Tabela 3 - Canais de comercialização

\begin{tabular}{ccc}
\hline & \multicolumn{2}{c}{ TOTAL } \\
\cline { 2 - 3 } Canais de comercialização & $\mathbf{N}^{\mathbf{0}}$. de empresas & (\%) Média de utilização \\
\hline Representante comercial & 8 & $36,7 \%$ \\
Licitação & 5 & $22 \%$ \\
Venda direta ao cliente & 6 & $22,3 \%$ \\
Lojas da fábrica & 3 & $3,7 \%$ \\
Vendedores próprios & 5 & $15,3 \%$ \\
\hline Total & & $\mathbf{1 0 0 , 0 \%}$ \\
\hline
\end{tabular}

Quanto aos fatores que são decisivos no processo, o elemento "preço" é o principal fator de decisão na hora da compra, seguido da marca do produto e tradição da empresa. Segundo depoimento dos empresários, $22 \%$ das vendas são realizadas por meio de licitações, o que explica em parte a adoção do preço do produto como principal fator de decisão de compra. Porém, as empresas não podem perder de vista o segundo fator decisivo apresentado pelos empresários foi justamente a marca e tradição dos produtos, o que revela preocupação com a qualidade.

\subsection{Instituições de ensino e de apoio}

As instituições que figuram como envolvidas nas atividades do setor são: Sindimetal, Secretaria da Indústria e Comercio, Associação Comercial e Industrial, SEBRAE, SENAI, SESI, IEL, Secretaria da Qualificação Profissional, TECPAR, UTFPR, e UEPG. Estas dispõem de profissionais habilitados a atuar nos mais diversos ramos de atividades. São ofertados cursos de média duração nas mais diversas áreas: gestão, informática, qualidade, segurança no trabalho, 
mecânica entre outros. Os cursos básicos necessários ao chão de fábrica, tais como solda, pintura, torneiro entre outros são programados de acordo com a demanda.

Várias instituições dispõem de programas de convenio para oferta de estagiários em diversos níveis. Algumas empresas que demandam cargos cuja qualificação seja de ensino superior, relativos à engenharia de produção acabam tendo que recrutar fora, tendo em vista que a cidade ainda não oferece formação nesta área.

Os serviços de consultoria/assessoria são oferecidos por diversas instituições para assuntos relacionados à exportação, legislação tributária, auxílio à certificação de produtos e serviços, prospecção de mercados entre outros. Mesmo assim, algumas dessas consultorias não são contratadas com muita freqüência. Percebe-se que várias instituições realizam as mesmas atividades de apoio que outras. Pode se dizer até que algumas destas instituições concorrem entre si no atendimento às necessidades do setor, principalmente no que diz respeito à oferta de atividades de consultoria e/ou assessoria às empresas.

Foi observado um baixo nível de interação entre as instituições e as empresas. Uma das forças centrípetas das aglomerações são os spillovers ou transbordamentos de conhecimento e tecnologia, que ocorrem devido à proximidade geográfica, que facilita o processo de circulação das informações e conhecimento entre as empresas. Assim sendo, esta baixa interação entre as empresas e as instituições de apoio não traz à existência os transbordamentos tecnológicos, fundamentais para o aumento da capacidade inovadora, sem a qual a aglomeração perde consideravelmente sua competitividade frente a outros concorrentes. Muitas das inovações que existem no setor foram sempre trazidas de fora, copiadas de outras regiões onde as empresas lá localizadas provavelmente investem mais em pesquisas de mercado e de novos produtos. Mas tanto as empresas as instituições de apoio sinalizaram que a situação atual de interação não é satisfatória.

\subsection{Inovação tecnológica}

Nenhuma das empresas do setor possui um departamento interno específico para o desenvolvimento de produtos e ou pessoal específico para desenvolver atividades de P\&D\&I. As pessoas que desempenham estas atividades têm outras funções na empresa, geralmente sendo técnicos da produção, ou os próprios sócio-proprietários que, com a experiência trazida de outras empresas, desenvolvem os modelos de produtos. As principais fontes de informação para inovação de processo, tanto para maquinário, quanto para a organização da produção são provenientes de funcionários que trabalharam em outras empresas, vendedores, clientes, publicações especializadas, fornecedores de maquinário, feiras e exibições, e visitas a outras empresas da região. Quanto a concepção e desenvolvimento de novos produtos, as principais fontes de informação as 
especificações de clientes, imitação de produtos de concorrentes externos ao setor, catálogos, revistas e sites especializados na Internet; visitas a feiras em outras regiões do país, e imitação de produtos de concorrentes locais.

\subsection{Gestão da qualidade}

O controle de qualidade é realizado de maneira informal, pelos próprios encarregados de produção, através de controle visual dos produtos quando ao final da linha de produção. O reflexo desta situação acontece no percentual de não-conformidade da produção, que corresponde a 3,47\% de índice médio de não conformidade entre todas as empresas do setor, num montante de 2.123 toneladas de produção não conforme. A estas toneladas de produção não conformes deve-se adicionar os custos de produção, tais como a mão-de-obra, energia, entre outros. Algumas empresas chegam mesmo a apresentar um percentual de $10 \%$ de produção não conforme. Uma vez que estes dados são apenas estimados, uma vez que o controle não é realizado de maneira estruturada, estes índices podem até ser até mais elevados.

A realização de testes de produtos ocorre em $86,67 \%$ das empresas, e são os testes de funcionamento e resistência ou capacidade de carga em se tratando de produto novo. Quando se trata de produto já existente, ocasionalmente são realizados testes de corrosão, em sua grande maioria dentro da própria indústria. Apenas duas empresas declararam já haver realizado algum tipo de teste por instituição credenciada.

Apenas uma das empresas utiliza o Controle Estatístico de Processos (CEP), e outra possui a certificação ISO 9001/2000.

\section{Conclusões e recomendações}

A pesquisa teve como principal objetivo caracterizar o setor de Móveis de Metal e Sistemas de Armazenagem e Logística segundo as principais tipologias de aglomerações produtivas encontradas na literatura. Após a análise dos dados, algumas conclusões foram alcançadas.

O capital humano precisa de atenção por parte da maioria das empresas, tanto a forma de gestão quanto a mão-de-obra e qualificação do chão-de-fábrica. A forma de gestão precisa de qualificação profissional, visando absorver novas técnicas que trariam uma grande melhoria nos processos administrativos e produtivos, refletindo diretamente na qualidade dos produtos. Esta qualificação pode ser realizada a baixo custo através de cursos de aperfeiçoamento oferecido pelas instituições de apoio. 
O treinamento para o chão-de-fábrica é realizado em serviço, caracterizando-se no estilo "learning-by-doing", o que apresenta um baixo índice de satisfação quanto à qualidade do aprendizado. Sugere-se que as empresas realizem cursos de qualificação e treinamento de forma compartilhada, tendo o intermédio das instituições de apoio. Isto proporciona menor custo para todas as empresas e melhoria dos processos produtivos, redução de desperdício de materiais e energia, e redução de produção não-conforme, que ocorre em função da imperícia dos trabalhadores.

As relações de cooperação horizontal ocorrem apesar de os empresários negarem sua existência. A cooperação vertical precisa ser fomentada, tanto entre as empresas e os fornecedores quanto entre as empresas e as instituições de apoio. As pretensões de cooperação futura e compartilhamento das atividades foram identificados como desejáveis, indicando que se pode atingir um nível satisfatório de eficiência coletiva no setor. Estas relações de cooperação são vitais para a existência, crescimento e maturidade de uma aglomeração produtiva em qualquer estágio de desenvolvimento.

As empresas não fazem investimentos diretos em P\&D\&I. Em sua maioria, as inovações que ocorrem são trazidas de outras localidades, configurando-se em cópia de produtos.

As empresas precisam buscar melhoria na qualidade, tanto de gestão quanto de processos e produtos. Esta ausência de controle de qualidade eleva as perdas na produção e reduzem a produtividade, consequentemente diminuindo a competitividade das empresas individual e coletivamente.

A aglomeração de empresas em estudo, seguindo a classificação de Frigero (2006), trata-se de agregação produtiva menor.

Segundo a classificação de Lastres e Cassiolato (2003), trata-se de um APL, pois apresenta os principais fatores característicos: aglomeração territorial de agentes econômicos, políticos e sociais com foco em um conjunto específico de atividades econômicas e que apresentam vínculos mesmo que incipientes.

Seguindo a classificação de Suzigan (2003), trata-se de um NDSR, que é o estágio mais avançado de uma aglomeração produtiva em sua metodologia, pois apresenta significativa contribuição para a região e para o setor econômico. Porém, em termos de processo evolutivo e de interação entre os atores, a aglomeração está em seu estágio embrionário, tendo em vista que a cooperação existente entre as empresas do setor é ainda incipiente.

Contudo, a correta conceituação da aglomeração não é fator condicionante de sucesso. Bem mais importante do que conceitua-la é perceber que o sucesso do setor como aglomeração produtiva depende da iniciativa privada e do trabalho conjunto dos empresários do setor. O sucesso dependerá se as ações de cooperação, manifestas como desejáveis na pesquisa de campo, de fato 
ocorrerem. Para tanto, cabe aos agentes locais e, principalmente, aos empresários organizarem-se no sentido de que a aglomeração contemple também outras características essenciais de um APL.

\begin{abstract}
The purpose of this study was to characterize the productive agglomeration of the Steel Furniture and Storage and Logistics Systems sector, located in Ponta Grossa, PR, according to the typologies present in the literature. An exploratory research by accessibility was carried out, using quantitative approach and complementary qualitative procedures. The data was collected through a questionnaire and interviews with the owner businessmen. The analysis shows that the referred agglomeration is one in the embrionary stage of evolution concerning the interaction among the actors.
\end{abstract}

Palavras-chave: Productive Agglomerations of Companies, Steel Furniture, Storage and Logistics Systems.

\title{
Referências
}

CASAROTTO Filho, Nelson; PIRES, Luis H. Redes de pequenas e médias empresas e desenvolvimento local: estratégias para a conquista da competitividade global. $2^{\circ}$ edição. São Paulo: Atlas, 2001.

CASSIOLATO, José. E.; LASTRES, Helena M.; MACIEL, Maria L. (orgs.) O foco em arranjos produtivos e inovativos locais de micro e pequenas empresas. In: "Pequena empresa: cooperação e desenvolvimento local". Rio de Janeiro: Relume Dumará, 2003.

CHIAVEnATO, Idalberto. Teoria Geral da Administração. Rio de Janeiro: Editora Campus, 2004.

ENRICO, Callegati; GRANDI, Silvia. Cluster Dynamics and Innovation in SMEs: The role of culture. International Centre for Research and the Economics of Culture, Institutions, and Creativity (EBLA). Dipartamento di Economia"S. Cognetti de Martis". Università di Torino. Working paper $n^{\circ}$ 03, 2005.

FRIGERO, Bruno M. A Transformação do modelo Italiano. 1980-2005. $1^{\circ}$ Encontro dos APLs do Paraná. Rede APLs Paraná. Curitiba: CIETEP, 2006.

GARCIA, Renato. Vantagens competitivas de empresas em aglomerações industriais: um estudo aplicado à industria brasileira de calçados e sua inserção nas cadeias produtivas globais. Tese de Doutorado: UNICAMP, 2001.

GIL, Antonio C. Métodos e Técnicas de Pesquisa Social. 5ª Ed. São Paulo: Atlas, 1999.

KRUGMAN, Paul. Geography and trade. Cambridge: MIT Press, 1991.

KRUGMAN, Paul. What's new about the New Economic Geography? Oxford review of economic policy, v. 14 , n.2. (1998a).

KRUGMAN, Paul. The role of geography in development. Annual World Bank Conference on Development Economics. Washington-DC, 1998 b.

LAKATOS, Eva M.; MARCONI, E.M. Fundamentos de metodologia Científica. 4 a ed. São Paulo: Atlas, 2001.

MARSHALL, Alfred. Industry and Trade: A Study of industrial technique and businnes organization; and of their influences on the condition of various classes and nations. On-line book. 1920. Disponível em <

http://www.econlib.org/library/marshall/marPtoc.html> Acesso em: novembro de 2005. 
MEYER-STAMER, Jörg; HARMES-LIEDTKE, Ulrich. How to Promote Clusters. Competitividad: Conceptos $Y$ Buenas Practicas. Uma Herramienta de Autoaprendizage Y Consulta. Inter-American Development Bank. Duisbrug and Buenos Aires, 2005.

PAGANI, Regina N.; et al. Móveis de metal e sistemas de armazenagem e logística: uma análise prévia do setor para a estruturação do APL da Região dos Campos Gerais, PR. XXVI ENEGEP. Anais... Fortaleza. Brasil. Outubro de 2006a.

PORTER, Michael E. A vantagem competitiva das nações. Rio de Janeiro: Campus, 1990.

PORTER, Michael E. Clusters and the New Economics of Competition. Harvard Business Review, Vol. 6, 77-90. Boston, Nov/Dez: 1998.

PORTER, Michael E. Clusters e Competitividade. HSM Management. N. 15, anos 3 Julho/agosto: 1999.

PORTER, Michael E. Clusters and competitiveness: findings from the cluster mapping project. In: Corporate strategies for the digital economy. Sloan Industry Centers. Cambridge, April 12, 2001.

SEPL (Secretaria de Estado do Planejamento do Paraná e Coordenação Geral); IPARDES (Instituto Paranaense de Desenvolvimento Econômico e Social). Arranjos Produtivos no Paraná: Identificação, Caracterização, Construção de Tipologia. Curitiba: Ipardes, 2006.

SCHMITZ, Hubert. Eficiência Coletiva: caminho de crescimento para a indústria de pequeno porte. Ensaios FEE. Porto Alegre, v.18, n.2, p.164-200, 1997.

SCHMITZ, Hubert. Collective efficiency and increasing returns. IDS Working paper no. 50. Institute of Development Studies. University of Sussex, Brighton. March, 1998.

SILVA, E. L., MENEZES. E. M. Metodologia da pesquisa e elaboração de dissertação. 3 a ed. Florianópolis: Laboratório de Ensino a Distância da UFSC, 2001.

SUZIGAN, W. et al. Sistemas Locais de Produção: Mapeamento, Tipologia e Sugestões de Políticas. Anais... XXXI Encontro Nacional de Economia. 2003.

SUZIGAN, Wilson. Aglomerações industriais: avaliação e sugestões de políticas. Disponível em: $<$ http://www.desenvolvimento.gov.br/arquivo/sti/publicacoes/ futAmaDilOportunidades/futIndustria_01.pdf>. 2000. Acesso: maio de 2005.

YIN, Robert K. Estudo de Caso: planejamento e métodos. Porto Alegre: Bookman, 2001.

\section{Dados dos autores:}

Regina Negri Pagani

Universidade Tecnológica Federal do Paraná - Campus Ponta Grossa / União de Ensino Vila Velha S/C Ltda.

Professora

Rua Francisco Camerino, 123. Vila Órfãs. Ponta Grossa - PR. 84 015-110

Telefone: (42) 3027-25-96

e-mail: jrpagani@uol.com.br

Luis Mauricio de Resende

Universidade Tecnológica Federal do Paraná - Campus Ponta Grossa -

Professor do Programa de Pós-graduação em Engenharia de Produção

Rua Frederico Hilgemberg, 30

Ponta Grossa - PR

CEP: 84015750

Telefone: (42) 32204816

e-mail:1mresende@utfpr.edu.br 
Recebido para publicação em: 02/10/2006

Aceito para publicação em: 10/03/2007 